UDK: 551.588.7:005.936.5

Stručni rad

Primljeno: 4. 10. 2021.

Prihvaćeno za štampu: 17. 11. 2021.

\author{
Dr. sc. Fatima Muhamedagić, docent \\ Univerzitet u Bihaću \\ Biotehnički fakultet \\ E-mail:fatima.muhamedagi@@gmail.com
}

Mr. sc. Anita Ramulić-Mujkić, v. as.

Univerzitet u Bihaću

Islamski pedagoški fakultet

E-mail:anita_ramuli@@yahoo.com

\title{
ČOVJEKOV UTICAJ NA OKOLIŠ S AKCENTOM NA OTPAD
}

\section{Sažetak}

Covjek sa stanovišta ekologije predstavlja jedan od nezaobilaznih ključnih ekoloških faktora okoliša koji se, pored ostalog, iærazito pojavljuje u segmentu nastanka otpada i u segmentu upravljanja otpadom. Sa stanovista islama on je namjesnik koji remeti stanje $i$ čni nered u okolisu. Covjekov uticaj u segmentu nastanka otpada cesto se pored okolišnog i pravnog aspekta sagledava i s religijskog aspekta.

Otpad prema nacionalnoj definiciji u Bosni $i$ Hercegovini podrazumijeva sve tvari ili predmete koje vlasnik odlaže, namjerava odložiti ili se traži da budu odložene u skeladu s jednom od kategorija otpada navedenoj u listi otpada.

U današnjem vremenu problematika otpada predstavlja dio globalnih ekoloških problema savremenog svijeta u kojem je covjek, sa svojim aktivnostima, odlučujući faktor u mijenjanju okoliša. Sve aktivnosti povezane su uglavnom s njegovim zadovoljavanjem potreba. U veri s tim postoje i mehanizmi regulacije koji se najččsce u našoj remlji oslanjaju na pravnu regulativu. Pored pravnih mehanizama postoje $i$ religijski (islam) i ekološki mehanižmi.

Ključne riječi: čovjek, ekološki faktor, otpad, pravna regulativa 


\section{UVODNI DIO}

Zbog velikih količina otpada i njegove štetnosti po okoliš, otpad se pored efekta staklenika, klimatskih promjena, onečišćenja medija okoliša, smanjenja biodiverziteta i drugo smatra, također, jednim od nezaobilaznih globalnih ekoloških problema današnjice. Globalni ekološki problemi pored neracionalnog odnosa i rascjepa između samog čovjeka i prirode, nastali su i kao posljedica djelovanja različitih izvora zagađenja (Muhamedagić i sar., 2020).

Čovjek je nezaobilazan ekološki faktor koji ima dominantnu ulogu u „proizvodnji“" otpada. On svojim aktivnostima predstavlja odlučujući faktor u mijenjanju okoliša, tj. čovjek je jedino živo biće na Zemlji/dunjaluku koje proizvodi otpad te time remeti stanje i čini nered u okolišu, jer kada je Allah odredio da će na Zemlji stvoriti i postaviti svog namjesnika, meleki su rekli: „Zar ćeš na Zemlji stvoriti onoga ko će na njoj činiti nered“ (El-Bekare, 30. ajet). Pored čovjekove proizvodnje otpada razlog mnoštva otpada je rasipništvo i nekontrolisano bacanje viška onoga što mu i ne treba, a na što se opominje u ajetu ,Jedite i pijte, ali ne pretjerujte, jer Allah ne voli one koji pretjeruju“ (El-A'raf, 31. ajet).

Prema literaturnim navodima Reimersa (1991) život na Zemlji unutar biosfere je smješten u samo 21.772 metra, što jasno ukazuje na osjetljivost i ograničenost prostora za sve članove živog svijeta te prateći nastali otpad njihovog bivstvovanja.

Postoji niz definicija o otpadu. Naprimjer, otpad (eng. waste) označava nešto odbačeno, što trenutnom vlasniku nije potrebno i odlaže se na okolišno prihvatljiv način (Direktiva EU, 2008). Prema nacionalnoj definiciji otpada u Bosni i Hercegovini „otpad“ označava sve materije ili predmete koje vlasnik odlaže, namjerava odložiti ili traži da budu odložene u skladu s jednom od kategorija otpada navedenoj u katalogu (Sl. novine F BiH, br: 33/03, 72/09, 92/17; Sl. glasnik BD, br: 0-02022-171/04; Sl. glasnik RS, br: 36/09, 88/10 i 14/16).

U praksi se može susresti još niz definicija koje slikovito određuju pojam otpada kao: zbir proizvodnih i potrošačkih navika, jasan otisak materijalnog života ljudi, nedovoljno otkriven izvor sirovina i energije, promjenljiv zbir različitih materija i energije ili roba s pozitivnom ili negativnom tržišnom vrijednosti i slično. Otpad nije gomila 
neiskorištenih materija i on sam po sebi nije smeće i ne mora postati smeće (otpad $\neq$ smeće).

Pojam smeće podrazumijeva mješavinu neodgovorno odbačenih i često dragocjenih otpadnih materija. Smeće je proizvod neprimjerenog ljudskog ponašanja. Znači, prema entitetskim zakonima $\mathrm{BiH}$, otpad nije i ne mora postati smeće, ali njegovim odbacivanjem i odlaganjem na odlagališta bila ona divlja, neuređena ili uređena, se bespovratno gube dragocjene materijalne i energetske vrijednosti otpada. Treba naglasiti da je i zakonski zabranjeno odlaganje otpada koji se može iskoristiti.

\section{KLASIFIKACIJA OTPADA}

Klasifikacija otpada vrši se na grupe, podgrupe i vrste otpada prema svojstvima i mjestu nastanka otpada, uzimajući u obzir kategorije otpada definisane prema katalogu otpada (Tabela br. 1).

Tabela br. 1. Katalog otpada-aktivnosti koje generiraju otpad (,,Sl. novine F BiH“, br: 9/05)

\begin{tabular}{|c|c|}
\hline Šifre & Vrste otpada \\
\hline $\begin{array}{ll}01 & 00 \\
00\end{array}$ & $\begin{array}{l}\text { Otpad koji nastaje kod istraživanja i kopanja ruda, iskopavanja } \\
\text { drobljenja kamenja i od fizičkog i hemijskog obrađivanja ruda; }\end{array}$ \\
\hline $\begin{array}{ll}02 & 00 \\
00\end{array}$ & $\begin{array}{l}\text { Otpad iz poljoprivrede, vrtlarstva, proizvodnje vodenih kultura, } \\
\text { šumarstva, lova i ribarstva, pripremanja hrane i prerade; }\end{array}$ \\
\hline $\begin{array}{ll}03 & 00 \\
00\end{array}$ & $\begin{array}{l}\text { Otpad od prerade drveta i proizvodnje ploča i namještaja, celuloze, } \\
\text { papira i kartona; }\end{array}$ \\
\hline $\begin{array}{ll}04 & 00 \\
00\end{array}$ & Otpad iz kožarske, krznarske i tekstilne industrije; \\
\hline $\begin{array}{l}0500 \\
00\end{array}$ & $\begin{array}{l}\text { Otpad od prerade nafte, prečišćavanja prirodnog gasa i pirolitičke } \\
\text { obrade uglja; }\end{array}$ \\
\hline $\begin{array}{l}0600 \\
00\end{array}$ & Otpad iz anorganskih hemijskih procesa; \\
\hline $\begin{array}{l}0700 \\
00\end{array}$ & Otpad iz organskih hemijskih procesa; \\
\hline
\end{tabular}




\begin{tabular}{|c|c|}
\hline $\begin{array}{l}0800 \\
00\end{array}$ & $\begin{array}{l}\text { Otpad od proizvodnje, formulacija, prodaje i primjene premaza (boje, } \\
\text { lakovi i staklasti emajli), ljepila, sredstava za zaptivanje i štamparskih } \\
\text { boja; }\end{array}$ \\
\hline $\begin{array}{l}0900 \\
00\end{array}$ & Otpad iz fotografske industrije; \\
\hline $\begin{array}{l}1000 \\
00\end{array}$ & Otpad iz termičkih postupaka; \\
\hline $\begin{array}{l}1100 \\
00\end{array}$ & $\begin{array}{l}\text { Otpad koji potječe od hemijske površinske obrade i zaštite metala; } \\
\text { hidrometalurgija obojenih metala; }\end{array}$ \\
\hline $\begin{array}{l}1200 \\
00\end{array}$ & $\begin{array}{l}\text { Otpad od oblikovanja i površinske fizičko-hemijske obrade metala i } \\
\text { plastike; }\end{array}$ \\
\hline $\begin{array}{l}1300 \\
00\end{array}$ & Otpadna tečna goriva i ulja (osim jestivog ulja, 05 i 12); \\
\hline $\begin{array}{l}1400 \\
00\end{array}$ & $\begin{array}{l}\text { Otpad od organskih materija koje se koriste kao rastvarači (osim } 07 \text { i } \\
\text { 08); }\end{array}$ \\
\hline $\begin{array}{l}1500 \\
00\end{array}$ & $\begin{array}{l}\text { Ambalaža; apsorbensi, materijali za upijanje, filterski materijali i } \\
\text { zaštitna odjeća koja nije specificirana na drugi način; }\end{array}$ \\
\hline $\begin{array}{l}1600 \\
00\end{array}$ & Otpad koji nije drugdje specificiran u katalogu; \\
\hline $\begin{array}{l}1700 \\
00\end{array}$ & $\begin{array}{l}\text { Građevinski otpad i otpad od rušenja objekata (uklj. i otpad od } \\
\text { izgradnje cesta); }\end{array}$ \\
\hline $\begin{array}{l}1800 \\
00\end{array}$ & $\begin{array}{l}\text { Otpad koji nastaje kod zaštite zdravlja ljudi i životinja i/ili srodnih } \\
\text { istraživanja (isključujući otpad iz domaćinstava i restorana koji ne } \\
\text { potječe iz neposredne zdravstvene zaštite); }\end{array}$ \\
\hline $\begin{array}{l}1900 \\
00\end{array}$ & $\begin{array}{l}\text { Otpad iz postrojenja za upravljanje otpadom, postrojenja za } \\
\text { prečišćavanje gradskih otpadnih voda i pripremu vode za piće i } \\
\text { industrijsku upotrebu; }\end{array}$ \\
\hline $\begin{array}{l}2000 \\
00\end{array}$ & $\begin{array}{l}\text { Komunalni otpad i slični otpad iz industrijskih i zanatskih pogona, } \\
\text { uključujući odvojeno prikupljene frakcije. }\end{array}$ \\
\hline
\end{tabular}


$\mathrm{Na}$ osnovu navedenih kategorija, a s obzirom na svojstva kojima otpad djeluje na zdravlje ljudi i okoliš, on se klasificira na: opasni otpad, neopasni otpad i inertni otpad.

Opasni otpad - predstavlja onu vrstu otpada koji posjeduje jednu ili više karakteristika (Pravilniku o kategorijama otpada sa listama opasan otpad je članom 3. okarakterisan sa 10 karakteristika) na osnovu kojih je kao takav opasan za život i zdravlje ljudi, okoliš ili imovinu, a u skladu je s kategorijama opasnog otpada onako kako je ta kategorija definisana u klasifikaciji otpada.

Neopasni otpad - je otpad koji nema neku od svojstava opasnog otpada. Inertni otpad - je ona vrsta otpada koja ne podliježe značajnim fizičkim, hemijskim ili biološkim promjenama.

Prema mjestu nastanka otpad se klasificira kao: komunalni otpad, tehnološki otpad i otpad iz domaćinstva.

Komunalni otpad - otpad iz domaćinstva kao i otpad iz proizvodne i/ili uslužne djelatnosti ukoliko je po svojstvima i sastavu sličan otpadu iz domaćinstva. U katalogu otpada je pod šifrom 20 te može biti i dijelom pod šifrom 15.

Tehnološki otpad - vrsta otpada koji nastaje u proizvodnom procesu u industriji, obrtu i drugim procesima, a po sastavu se razlikuje od komunalnog. U katalogu otpada može biti pod šiframa od 01 do 19.

Posebne kategorije otpada - čine ga: biootpad, tekstilni otpad i obuća, otpadna ambalaža, otpadne gume, otpadna ulja, otpadne baterije i akumulatori, otpadna vozila, otpad koji sadrži azbest, medicinski otpad, građevinski otpad, otpadni mulj iz uređaja za pročišćavanje otpadnih voda i slično.

Pored pomenutih klasifikacija otpada postoji i podjela prema agregatnom stanju a to je na: čvrsti otpad, tekući otpad i plinoviti otpad. Mjesta gdje se odlažu otpadi nazivaju se deponije ili odlagališta, a mogu biti: divlje deponije, komunalne deponije i sanitarne (okolišno prihvatljive) deponije. 


\section{UPRAVLJANJE OTPADOM}

Gledano kroz historiju i religijski aspekt, a posebno s aspekta islama vodilo se računa o zaštiti okoliša, otpadu, odnosno općenito čistoći u okolišu. Kada je u pitanju zaštita okoliša i u islamu postoje primjeri koji se vežu još za sedmo stoljeće, kada na drugim mjestima, mnoge stvari nisu bile regulisane.

Ono što učenje islama odvaja od učenja drugih vjera i drugih pogleda na svijet, jeste da je čovjek postavljen kao namjesnik Božiji na Zemlji (El-Bekare, 30. ajet) i što je on preuzeo emanet, kojeg nisu preuzeli ni nebesa, ni Zemlja, ni planine! (El-Ahzab, 72. ajet). Također, odlika čovjeka, u islamu, je što mu je sve na ovom svijetu/dunjaluku potčinjeno i dato na korištenje i upravljanje. $U$ islamu poslanik Muhammed, a.s., je podsticao na čišćenje dvorišta i održavanja čistoće tjela i čistoće u okolišu „Čistoća je pola vjere“ (Muslim, 2004) dovoljno ukazuje na to koliku je važnost pridavao čišćenju.

U islamu čistoća je jedan od sastavnih dijelova vjerovanja. Naprimjer, uslovi ispravnosti namaza su čistoća tijela, odjeće i mjesta na kojem se klanja, a o čemu govori i hadis koji prenosi Sevban, r.a., od Muhammeda, a.s., i kaže: "Trudite se koliko ste u mogućnosti i budite umjereni, te znajte da je od vaših najboljih djela namaz, a abdest ( $\mathrm{tj}$. čistoću) čuva i pazi samo vjernik."

U literaturnom izvoru Ogranci imana (Sedić, 2008) se navodi da je poslanik Muhammed posebno pohvalio uklanjanje s puta svega onoga (grane, staklo i slično - općenito otpad) što smeta prolaznicima jer je poslanik Muhammed rekao: „Prikazana su mi dobra i loša djela mog ummeta, pa sam vidio da je od najboljih djela maknuti s puta ono što smeta, a od loših djela ostaviti prljavštinu u džamiji.“2 Poslanik, s.a.v.s., bio je uzor jer je lično uklanjao nečistoću u džamiji. On se posebno pohvalno izrazio prema ženi, crnkinji, koja je čistila džamiju jer kada je ona umrla, on o tome nije bio obavješten i naknadno joj je otišao na mezar i klanjao dženazu.

Također, kada je poslanik Muhammed pitan od Ebu Berze, r.a. da ga poduči nečem što će mu koristiti on mu je rekao: „Sklanjaj s puta ono

\footnotetext{
${ }^{1}$ Izvor: Šuabul-iman, $3 / 5$.

${ }^{2}$ Izvor: Hadis je zabilježio Muslim.
} 


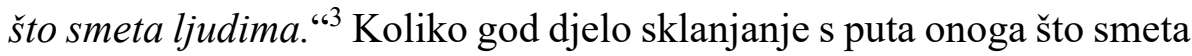
prolaznicima izgleda beznačajno i nevažno, ipak se za njega obećava velika nagrada, što je ukazano hadisom jer je poslanik Muhammed rekao: „Jednom prilikom je neki čovjek išao putem i naišao je na bodljikavu granu, pa ju je smaknuo. Allah, dž.š. mu je na tome zahvalio $i$ grijehe mu oprostio. “4 Uzvišeni Allah kaže „A oni koji vjernike i vjernice uznemiravaju, a oni to ne zaslužuju, tovare na sebe klevetu i očiti grijeh" (Sura El- Ahzab, 58. ajet). Sve ovo je ubrojao u sastavne dijelove vjerovanja: „Islam se sastoji od sedamdeset $i$ nekoliko dijelova, najvažnije je reći La ilahe illellah / Nema Boga osim Allaha, a posljednje je smaknuti s puta ono što smeta prolaznicima“"5 (muttefekun alejhi).

Poznato je da je poslanik Muhammed a.s. opominjao na neželjeno onečišćenje u okolišu i zabranio da se vrši nužda na izvorima vode, na putu i u hladu: „Čuvajte se troga što prokletstvo izaziva: obavljanje nužde na izvorima vode, na putu i u hladu" (Edu Davud, Ibnu Madže i Ibnu Hibban), te: „Ko obavi veliku nuždu na putu kud prolaze ljudi zaslužio je prokletstvo Allaha, dž.š. i svih ljudi،6 kao i poticao da dvorišta (okoliš) budu čista „Držite čista vaša dvorišta (okoliš).“7 Također, poslanik Muhammed je rekao da se ljudi čuvaju triju kletvi! „Obavljanje nužde u mjestu gdje ljudi hladuju, na putu kud hodaju $i$ pored mjesta gdje se skuplja voda." Ovim primjerima se ukazuje da su temelji održavanja čistoće u okolišu (bez otpada) dati još u islamu u vrijeme poslanika Muhammeda a.s. U ajetima sure El-Bekare jasno je istaknuto: „A kada im se kaže: „Ne činite nered na Zemlji“ oni vele, „Mi red pravimo. " A nije tako. Oni stvarno, bezosjećajno, nered čine“" (El-Bekare, 11. i 12. ajet).

Ono što je primjetno iz mnogih kur'anskih ajeta jeste da se čovjek poziva na razmišljanje, promišljanje, uzimanje pouke, zaključivanje, itd. gdje se traži njegov puni angažman u ovom svijetu/dunjaluku gdje živi, da bude subjekt zbivanja, a ne objekt zbivanja. Svakako, uvijek se

\footnotetext{
${ }^{3}$ Izvor: Hadis je zabilježio Muslim.

${ }^{4}$ Izvor: Hadis su zabilježili Buharija i Muslim

${ }^{5}$ Izvor: Hadis su zabilježili Buharija i Muslim.

${ }^{6}$ Izvor: Taberani i Bejheki sa slabim senedom.

${ }^{7}$ Izvor: Hadis je zabilježio Muslim
} 
uzimaju u obzir vremenske i materijalne prilike, jer: „, (...) Mi nikoga preko njegove mogućnosti ne zadužujemo!“" (El-En'am, 152. ajet).

Veoma je važna usklađenost praktične primjene i ličnih primjera $u$ svakom segmentu djelovanja čovjeka pa tako i segment upravljanja otpadom. Uzvišeni Allah upućuje oštar prigovor onima koji nemaju usaglašen govor i djelo (praktična primjena i djelo), pa kaže: „O vjernici, zašto jedno govorite a drugo radite? O, kako je Allahu mrsko kada govorite riječi koje djela ne prate!" (Es-Saff, 2. i 3. ajet), te opominje “...i ne čini nered po Zemlji, jer Allah ne voli one koji nered čine“ (El-Kasas, 77. ajet).

U današnjem savremenom društvu u segmentu upravljanja, odnosno integralnog načina upravljanja otpadom uveliko se posvećuje pažnja i pokušavaju riješiti nastali problemi. Sistem upravljanja otpadom je važan sastavni dio svakog modernog društva, a za njegovo razvijanje i efikasnost važne su ekonomske odrednice koje potiču smanjivanje količine otpada na mjestu nastanka, odvojeno sakupljanje, obradu, recikliranje $\mathrm{i}$ oporavak te usmjeravanje $\mathrm{i}$ kontinuirani razvoj navedenog.

Oblast upravljanja otpadom u Bosni i Hercegovini definisana je entitetskim zakonima o upravljanju otpadom kojima se na nov način, $u$ skladu s Direktivama EU tretira problem otpada. U BiH na entitetskom nivou (naprimjer, Federacije $\mathrm{BiH}$ ) u cilju postizanja cilja i pravovremenog sprečavanja zagađivanja i smanjenja posljedica po zdravlje ljudi i okoliš, definisani su prioriteti u upravljanju otpadom (Sl. Novine F BiH, br: 33/03, 72/09, 92/17) na način da se osigura:

- minimalno nastajanje otpada, a posebno svođenje opasnih karakteristika na minimum;

- smanjenje nastalog otpada po količini, posebno uzimajući u obzir tokove otpada;

- tretiranje otpada na način kojim se osigurava povrat sirovinskog materijala iz njega;

- spaljivanja ili odlaganja na deponije, na okolinski prihvatljiv način onih vrsta otpada koje ne podliježu povratu komponenti, ponovnoj upotrebi ili proizvodnji energije. 
Općenito u Evropskoj Uniji, postoji pozitivan opći koncept upravljanja otpadom tzv. 4R (Reduce, Reuse, Recycle i Recover) + 3E (Educate, Economise i Enforce). Naprimjer, Tjell (2005) navodi da je u EU razrađen pristup, poznat kao princip hijerarhije otpada (eng. waste hierarchy princip) koji uključuje izbjegavanje stvaranja otpada $\mathrm{i}$ reklamiranje njegove prerade, reciklaže i kompostiranja, ponovne upotrebe i spaljivanja.

U području upravljanja otpadom se već dugi niz godina provode aktivnosti i mjere koje doprinose približavanju zadanim strateškim ciljevima, no ipak u nekim segmentima ti ciljevi se, nažalost, ne provode ili su prisutne poteškoće u njihovom provođenju. Iz pomenutog razloga potrebno je jačanje kapaciteta tijela nadležnih institucija za upravljanje otpadom, povećavanje broja učesnika u segmentu upravljanja otpadom, permanentno razvijanje i unapređivanje ekonomskih instrumenata. Posebno mjesto $u$ dijelu upravljanja otpadom zauzima potreba obrazovanja stručnjaka za potrebe raznih privrednih djelatnosti koji će se baviti problematikom integralnog upravljanja otpadom.

\section{PRAVNA REgULATIVA U SEGMENTU UPRAVLJANJA OTPADOM}

U Bosni i Hercegovini tj. na državnom nivou još uvijek, nažalost, ne postoji zakonska regulativa u segmentu upravljanja otpadom. No, sve odredbe Direktive kao i uredbe nekih drugih direktiva uglavnom su uključene u entitetske zakone Bosne i Hercegovine o ovoj problematici.

Naprimjer Direktive:

- Okvirna Direktiva o otpadu EU 2008/98/EZ;

- Odluka Komisije 2000/532/EZ o definisanju liste otpada;

- Uredba (EZ) 2150/2002 Evropskog parlamenta i Savjeta o statistikama o otpadu;

- Direktiva Savjeta o deponijama 1999/31/EZ o odlaganju otpada na deponije;

- Direktiva Evropskog parlamenta i Savjeta 94/62/EZ o ambalaži i ambalažnom otpadu; 
- Direktiva 2000/53/EZ Evropskog parlamenta i Savjeta o otpadnim vozilima;

- Direktiva 2006/66/EZ Evropskog parlamenta i Savjeta o baterijama i akumulatorima i otpadnim baterijama i akumulatorima;

- Direktiva Savjeta 96/59/EZ o uklanjanju polihlorovanih bifenila i polihlorovanih terfenila (PCB/PCT);

- Direktiva 2006/21/EZ Evropskog parlamenta i Savjeta o upravljanju otpadom iz ekstrakcijskih industrija - Direktiva o rudarskom otpadu;

- Direktiva Savjeta 86/278/EZ o zaštiti okoliša, a naročito zemljišta, pri upotrebi otpadnog mulja u poljoprivredne svrhe;

- Uredba (EZ) br. 1013/2006 Evropskog parlamenta i Savjeta o transportu otpada;

- Direktiva 2012/19/EU Evropskog parlamenta i Savjeta o električnom i elektronskom otpadu (EEO).

Naprimjer, na entitetskom nivou - u Federaciji Bosne i Hercegovine postoji trenutno 20 pravnih akata koji regulišu ovaj segment:

- Zakon o upravljanju otpadom (,Sl. novine F $\mathrm{BiH}^{“,}$ broj 33/03, 72/09 i 92/17);

- Pravilnik o kategorijama otpada sa listama (,,Sl. novine F BiH“, broj 9/05);

- Pravilnik o izdavanju dozvole za aktivnosti male privrede u upravljanju otpadom (,Sl. novine F BiH“, broj 9/05);

- Pravilnik o potrebnim uslovima za prenos obaveza sa proizvođača i prodavača na operatera u sistemu za prikupljanje otpada (,Sl. novine F BiH“, broj 9/05);

- Pravilnik koji određuje postupanje sa opasnim otpadom koji se ne nalazi na listi otpada ili čiji je sadržaj nepoznat (,Sl. novine F BiH“, broj 9/05);

- Pravilnik o sadržaju plana prilagođavanja otpadom za postojeća postrojenja za tretman ili odlaganje otpada i aktivnostima koje poduzima nadležni organ (,Sl novine $\mathrm{F} \mathrm{BiH}^{\prime}$, broj 9/05); 
- Uredba o vrstama finansijskih garancija kojima se osigurava prekogranični transport opasnog otpada (,Sl. novine $\mathrm{F} \mathrm{BiH}^{\prime \prime}$, broj 41/05);

- Uredba o finansijskim i drugim garancijama za pokrivanje troškova rizika od mogućih šteta, čišćenja i postupaka nakon zatvaranja odlagališta („Sl. novine F BiH“, broj: 39/06);

- Uredba o selektivnom prikupljanju, pakovanju i označavanju otpada (,Sl. novine F BiH“, broj 38/06);

- Uredba koja reguliše obavezu izvještavanja operatera i proizvođača otpada o sprovođenju programa nadzora, monitoringa i vođenja evidencije prema uslovima iz dozvole (,Sl. novine $\mathrm{F} \mathrm{BiH}^{“}$, broj 31/06);

- Pravilnik o obrascu, sadržaju i postupku obavještavanja o važnim karakteristikama proizvoda i ambalaže od strane proizvođača (,Sl. novine F BiH“, broj 6/08);

- Pravilnik o životinjskom otpadu i drugim neopasnim materijalima prirodnog porijekla koji se mogu koristiti u poljoprivredne svrhe (,Sl. novine F BiH“, broj 8/08);

- Pravilnik o upravljanju medicinskim otpadom (,Sl. novine F BiH“, broj 77/08);

- Pravilnik o upravljanju ambalažom i ambalažnim otpadom (,S1. novine broj: 88/11, 28/13, 8/16, 54/16, 103/16 i 84/17, 85/20);

- Pravilnik o upravljanju otpadom od električnih i elektronskih proizvoda (,Sl. novine $\mathrm{F} \quad \mathrm{BiH}^{“}$, broj: 87/12, 107/14, 8/16, 79/16 i 12/18);

- Pravilnik o uslovima za rad postrojenja za spaljivanje otpada (,S1. novine F BiH“", broj: 12/05);

- Pravilnik o prekograničnom kretanju otpada (,Sl. Novine F BiH“, broj: 07/11, 39/15, 25/19 i 19/21);

- Uredba o naknadama za plastiče kese tregerice (,Sl. novine F BiH”, broj: 9/14); 
- Uredba o informacionom sistemu upravljanja otpadom („Sl. novine F BiH“, br: 97/18);

- Pravilnik o građevinskom otpadu („Sl. novine F BiH“", broj: 93/19);

- Uredba o načinu raspodjele i ulaganja prikupljenih naknada za posebne kategorije otpada i uslovima za dodjelu poticajnih sredstava (,Sl. novine F BiH“, br: 59/21);

- Uredba o proizvodima koji poslije upotrebe postaju posebne kategorije otpada i kriterijima za obračun i način plaćanja naknada (,Sl. novine F BiH“', broj:59/21);

- Pravilnik o upravljanju otpadom iz proizvodnje titan dioksida (,Sl. novine $\mathrm{F} \mathrm{BiH}$ “, broj: 20/21).

\section{ZAKLJUČAK}

Zbog (ne)savjesnog ponašanja čovjeka kao jedinke, kao ključnog ekološkog faktora i kao jedinog bića koje „proizvodi“ otpad na Zemlji/dunjaluku kao posljedica često su prisutni problemi oko upravljanja otpadom.

Općenito problemi iz tematike upravljanja otpadom su vezani za svakodnevnu čovjekovu aktivnost. On kao jedinka, odnosno sastavni dio biosfere na Zemlji/dunjaluku, treba da u cilju održivosti i očuvanja okoliša bude svjestan svojih preuzetih obaveza i dužnosti. Preuzete obaveze i dužnosti sagledavajući s ekološkog, religijskog i pravnog aspekta se moraju ispoštovati, vodeći pritom računa o svim sastavnim dijelovima okoliša (tlo, zrak, voda, druga živa bića).

U cilju realizacije čovjekovih obaveza s religijske osnove, važne su opomene $\mathrm{i}$ ajeti te pozitivni primjeri iz ličnog života poslanika Muhammeda, a.s. jer ,,Vi u Allahovom Poslaniku imate divan uzor za onoga koji se nada Allahovoj milosti i nagradi na onome svijetu, $i$ koji često Allaha spominje.“ (El-Ahzab, 21. ajet) „Jer ti si, zaista, najljepše ćudi! "(El-Kalem, 4. ajet). Opomena “(...) i ne čini nered po Zemlji, jer Allah ne voli one koji nered čine. "(El-Kasas, 77. ajet) i također, važna opomena (...) Mi nikoga preko njegove mogućnosti ne zadužujemo! “ (El-En'am, 152. ajet). 
Ekološka osnova bazira se na principima minimizacije otpada na samom mjestu nastanka i njegove proizvodnje, korištenja povratne ambalaže, potom ambalažni materijal da se bazira na mogućnosti recikliranja i drugo. Općenito, ekološka osnova se bazira na poštovanju sistema integralnog načina upravljanja otpadom.

U radu je pored religijske i ekološke osnove definisana i pravna osnova (zakonski akti) koja je neizostavan dio demokratski uređenog pravnog sistema. Ovaj vrlo važan mehanizam pravne regulative se mora poštovani i efikasno provoditi da ne bude stavka deklaratornog karaktera, nego da je ista sprovodiva u praksi.

Cijela planeta Zemlja (biosfera)/dunjaluk je skup raznovrsnih ekosistema. Iako naizgled djeluje vrlo moćno, u suštini je vrlo osjetljivo i ranjivo područje samo iz činjenice da ono obuhvata, prema literaturnim podacima, vrlo mali interval prostiranja oko $22 \mathrm{~km} \mathrm{u}$ kojem se nalazi (je nemješten) cjelokupan živi svijet.

Koliko će čovjek, kao namjesnik i sastavnica okoliša, uspjeti ispoštovati preuzete dužnosti i obaveze pokazat će nadolazeće generacije poslije nas i vrijeme.

\section{LITERATURA}

Čaušević M. Dž. ef. i Pandža M. hfz. (1937) Kur'an Časni, Prevod i Tumač, Sarajevo (dostupno u pdf:

https://www.yumpu.com/xx/embed/view/LwCfT39OnIoquyGp, preuzeto: 27. 9. 2021.

Krznar, T. (2007) René Descartes i suvremeno shvaćanje prirode, Socijalna ekologija, 16 (1): 59-78.

Reimers, N. F. (1991) Poular Dictionary of Biology, The Academy of Science of the UUUR, Moscow.

Sedić F. (2008) Ogranci imana, El-Kelimeh, Novi Pazar.

Muhamedagić F., Cero M., Veladžić M., (2020) Ekologija i održivo upravljanje okolišem, Univerzitetski udžbenik, Bihać.

Muslim (2004) Muslimova zbirka hadisa, prijevod sa arapskog Mrahorović M., Prljača M., Karaman N., Karaman J., Mujezin A., El kalem, Sarajevo (dostupno u pdf: 
https://d1.islamhouse.com/data/bs/ih_books/bs_Muslimova_zbirka_hadis a_sazetak.pdf, preuzeto: 27. 10. 2021.

Tjell, C. J. (2005) Is the 'waste hierarchy' sustainable? (Editorial). U: Waste Management \& Research, 23:173-174.

Pravilnik o kategorijama otpada sa listama (,Sl. novine F BiH“, broj 9/05).

Direktiva EU (2008) Okvirna Direktiva o otpadu EU 2008/98/EZ

Zakon o upravljanju otpadom („Sl. novine F BiH“, broj 33/03, 72/09 i 92/17);

Zakon o upravljanju otpadom (Sl. glasnik RS, broj: 36/09-115, 88/10-170, 14/16-17, 95/18-267).

Zakona o upravljanju otpadom („Službeni glasnik Brčko distrikta $\mathrm{BiH}^{\circ}$, broj $5 / 04,1 / 05,19 / 07,2 / 08,9 / 09)$ 
Fatima Muhamedagić, $\mathrm{PhD}$

University of Bihac

The Biotechnical faculty

E-mail:fatima.muhamedagi@gmail.com

Anita Ramulić-Mujkić, MA

University of Bihac

Islamic Pedagogical Faculty

E-mail:anita_ramuli@@yahoo.com

\section{HUMAN IMPACT ON THE ENVIRONMENT WITH AN EMPHASIS ON WASTE}

\section{ABSTRACT}

From the point of view of ecology, human represents one of the unavoidable key ecological factors of the environment, which, among other things, is clearly manifested in the segment of waste generation and in the segment of waste management. From the standpoint of Islam, human is a governor who disturbs the situation and makes a mess in the environment. Human's influence in the segment of waste generation is often, in addition to the environmental and legal aspects, also viewed from the religious aspect.

According to the national definition in Bosnia and Herzegovina, waste means all substances or objects that the owner disposes of, intends to dispose of or is required to be disposed of in accordance with one of the waste categories listed in the waste list.

Nowadays, the issue of waste is part of the global environmental problems of the modern world in which human, with his activities, is a decisive factor in changing the environment. All activities are mainly related to meeting his needs. In this regard, there are regulatory mechanisms that most often in our country rely on legal regulations. In addition to legal mechanisms, there are also religious (Islam) and environmental mechanisms.

Key words: human, ecological factor, waste, legal regulations 
الأستاذة المحاضرة فاطمة محمد آغيتش

جامعة بيهاتش

كلية التقنية الحيوية

fatima.muhamedagic@gmail.com

خريجة كلية الحقوق السيدة أنيتا راموليتش مويكيتش

جامعة بيهاتش

كلية التربية الإسلامية

anita_ramulic@yahoo.com

تأثير الإنسان على البيئة وعلى النفايات بشكل خاص

\section{الخلاصة}

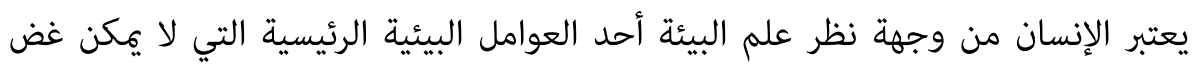

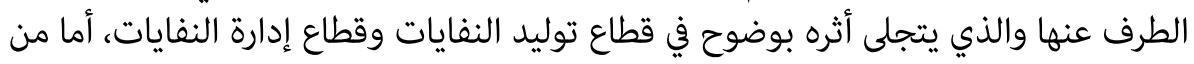

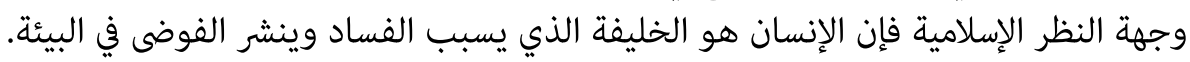

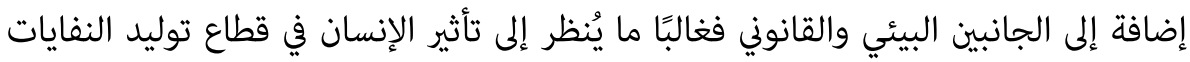
من الجانب الديني أيضًا.

وفقًا للتعريف الوطني في البوسنة والهرسك فإن النفايات تتضمن جميع المواد أو الأشياء التي

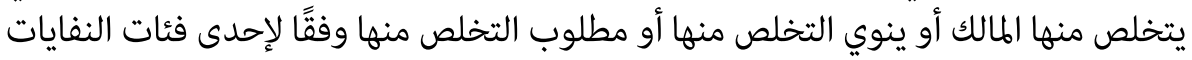
المدرجة في قائمة النفايات.

تعد قضية النفايات في الوقت الحاضر جزءًا من المشكلات البيئية العامة في العام الحديث،

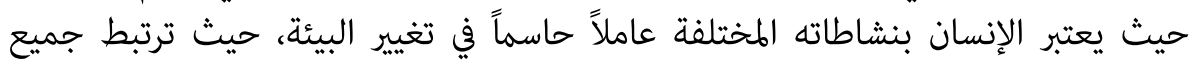

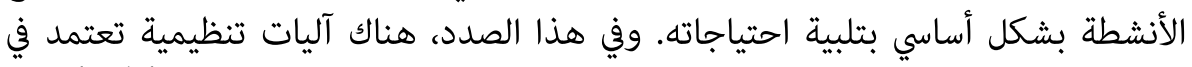

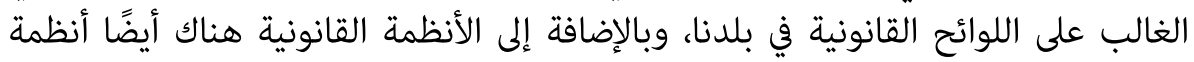

$$
\text { دينية (إسلامية) وبيئية. }
$$

الكلمات المفتاحية: إنسان، عامل بيئي، نفايات، لوائح قانونية. 